\title{
PERAN KADER SEBAGAI TENAGA PELAKSANA ELIMINASI PROGRAM PEMBERIAN OBAT PENCEGAHAN MASSAL LIMFATIK FILARIASIS TAHAP III DI KABUPATEN BANYUASIN
}

\author{
Indah Margarethy ${ }^{1 *}$, Reni Oktarina ${ }^{2}$ \\ ${ }^{1}$ Balai Penelitian dan Pengembangan Kesehatan Baturaja \\ Jl. A.Yani KM.7 Kemelak Baturaja, 32111, Kabupaten Ogan Komering Ulu, Sumatera Selatan, Indonesia \\ ${ }^{2}$ Badan Penelitian dan Pengembangan Daerah \\ Provinsi Sumatera Selatan, Jl. Demang Lebar Daun No. 4864, Palembang, 30137, Kota Palembang \\ Sumatera Selatan, Indonesia
}

\begin{abstract}
Banyuasin Regency is a filariasis endemic area in South Sumatra Province with total 90 chronic cases reported in 2014 while in 2018 decreased to 46 cases. Strategic coordination and good cooperation from various parties are needed to achieve the goals of elimination of lymphatic filariasis, one of them is by involving community as cadres of community drug distributors (CDDs) in mass drug administration (MDA). This study aimed to determine the role of CDDs in (MDA) filariasis phase III in Banyuasin Regency. Data collection was carried out through indepth interviews with selected informants, namely: Filariasis Program director of the Banyuasin District Health Office, Filariasis Program director at puskesmas in Banyuasin Regency, village midwives, and cadres. This type of research is qualitative so informants are adjusted to the data requirements. The data obtained were analyzed using content analysis. The results showed the implementation of phase III MDA filariasis in Banyuasin Regency hadn't proceeded according to the procedure. In the implementation, the CDDs has a role in helping health workers to collect data on target populations and people who get drugs, socialize MDA activities to the people in their areas and distribute medicine at treatment posts and house to house. Obstacles in the field were the population who do not take medicine is not recorded, monitoring of drug side effects is not carried out due to the minimal number of CDDs, the budget was not optimal both for mobilization and training for CDDs.
\end{abstract}

Keywords: Limphatic filariasis, community drug distributor, mass drug administration, Banyuasin Regency.

\section{THE ROLE OF CADRES AS COMMUNITY DRUG DISTRIBUTORS IN MASS DRUG ADMINISTRATION (MDA) OF LYMPHATIC FILARIASIS PHASE III IN BANYUASIN REGENCY}

\begin{abstract}
Abstrak
Kabupaten Banyuasin merupakan daerah endemis filariasis di Provinsi Sumatera Selatan dengan jumlah kasus kronis yang dilaporkan pada tahun 2014 sebanyak 89 kasus dan pada tahun 2018 mengalami penurunan menjadi 46 kasus. Koordinasi strategi serta kerjasama yang baik dari berbagai pihak diperlukan untuk mencapai tujuan eliminasi filariasis, salah satunya dengan melibatkan kader sebagai Tenaga Pelaksana Eliminasi (TPE) dalam pengobatan massal filariasis. Tujuan penelitian ini untuk mengetahui peran TPE dalam pelaksanaan Pemberian Obat Pencegahan Massal (POPM) filariasis Tahap III di Kabupaten Banyuasin. Pengumpulan data dilakukan melalui wawancara mendalam dengan informan terpilih yaitu: Pengelola Pogram Filariasis Dinas Kesehatan Kabupaten Banyuasin, Pengelola Program Filariasis Puskesmas di Kabupaten Banyuasin, bidan desa, dan kader. Jenis penelitian ini adalah penelitian kualitatif maka jumlah informan disesuaikan dengan kebutuhan data. Data
\end{abstract}


yang diperoleh dianalisis menggunakan analisis konten. Hasil penelitian menunjukkan pelaksanaan POPM filariasis tahap III di Kabupaten Banyuasin belum berjalan sesuai dengan prosedur. Pada pelaksanaannya, TPE berperan membantu petugas kesehatan melakukan pendataan penduduk sasaran dan penduduk yang mendapatkan obat, mensosialisasikan kegiatan POPM ke masyarakat serta membagikan obat massal filariasis di pos pengobatan maupun rumah ke rumah. Kendala di lapangan yaitu penduduk yang tidak minum obat filariasis tidak tercatat, pengawasan terhadap efek samping obat tidak dilakukan karena minimnya jumlah TPE, anggaran untuk TPE masih minim baik untuk mobilisasi dan pelatihan khusus untuk TPE.

Kata Kunci: Filariasis limfatik, tenaga pelaksana eliminasi, POPM, Kabupaten Banyuasin.

Naskah masuk: 12 Juni 2020; Review: 17 Juli 2020; Layak Terbit: 15 Agustus 2020

*Alamat korespondensi penulis pertama: e-mail: indah_lokalitbang@yahoo.com; Telp: (0735) 325303

\section{PENDAHULUAN}

Indonesia saat ini masih menghadapi permasalahan pengendalian penyakit menular (emerging infection diseases), dengan munculnya kembali penyakit menular lama (re-emerging disease) dan penyakit menular baru (new emerging infection diseases). Salah satu penyakit menular yang masih menjadi masalah kesehatan masyarakat Indonesia yaitu filariasis atau kaki gajah. Filariasis adalah penyakit menular menahun yang disebabkan oleh cacing filaria yang ditularkan melalui gigitan nyamuk dan menyerang saluran dan kelenjar getah bening. Penyakit ini tidak menimbulkan kematian, namun dapat merusak sistem limfe, menimbulkan pembengkakan pada kaki, tangan, glandula mammae, dan scrotum, menimbulkan cacat seumur hidup serta stigma sosial bagi penderita dan

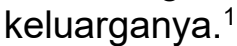

Filariasis telah menginfeksi 120 juta penduduk di 83 negara di seluruh dunia, terutama negara-negara di daerah tropis dan beberapa daerah sub tropis ${ }^{1}$. Negara endemik filariasis terbanyak di dunia adalah India kemudian di urutan kedua Indonesia dan ketiga terbanyak adalah Nigeria. ${ }^{2} \mathrm{Di}$ Indonesia penyakit ini tersebar hampir di seluruh wilayah Indonesia, di beberapa daerah mempunyai tingkat endemisitas yang cukup tinggi, terutama semua daerah di Sumatera dan Kalimantan yang telah terpetakan menjadi daerah endemis filariasis. Sejak tahun 2000 sampai 2009 terdapat 11.914 kasus kronis yang dilaporkan yang tersebar di 401 Kabupaten/Kota. ${ }^{3}$

Kabupaten Banyuasin merupakan salah satu daerah endemis filariasis tertinggi di Provinsi Sumatera Selatan, hal ini terlihat dari tahun 2008 sampai tahun 2011 tercatat 142 kasus filariasis kronis yang tersebar di 20 wilayah kerja puskesmas. ${ }^{4}$ Pada tahun 2018 Kabupaten Banyuasin juga masih menjadi kabupaten tertinggi diantara kabupaten lainnya di Provinsi Sumatera Selatan dengan kasus kronis sebanyak 46 orang. ${ }^{5}$

Pada tahun 2000 WHO menetapkan kesepakatan global untuk eliminasi penyakit kaki gajah (The Global Goal of Elimination of Lymphatic Filariasis as a Public Health problem by The Year 2020). Agenda utama program eliminasi filariasis adalah melaksanakan kegiatan pemberian obat pencegahan secara massal filariasis untuk memutuskan rantai penularan filariasis pada penduduk di semua kabupaten/kota endemis filariasis dan seluruh penderita filariasis dapat terjangkau pelayanan kesehatan yang memadai. ${ }^{1}$

Pemberian Obat Pencegahan Massal (POPM) filariasis dengan DEC (Diethyl Carbamazine Citrate) dan Albendazol di Kabupaten Banyuasin sudah dimulai dari tahun 2002 dan dilakukan secara bertahap di seluruh kecamatan. Berdasarkan data tahun 2011 cakupan 
pengobatan di Kabupaten Banyuasin hanya sebesar $56,1 \%{ }^{4}$. Hal ini masih jauh dari target yang ditetapkan WHO dimana terselenggaranya kegiatan POPM filariasis yang terencana dengan baik terhadap seluruh penduduk sasaran di kabupaten/kota endemis filariasis dengan cakupan $\geq 85 \%$ jumlah penduduk sasaran pengobatan dan $65 \%$ dari jumlah penduduk total. $^{1}$

Hasil penelitian Reni Oktarina dkk di Banyuasin ditemukan penderita positif baru di desa sentinel dan desa spot di Kabupaten Banyuasin dengan angka prevalensi mikrofilaria $<1 \%$ setelah pengobatan massal tahap III. Kepadatan mikrofilaria yang ditemukan di Kabupaten Banyuasin tergolong tinggi karena $>50$ per milliliter darah sehingga risiko penularannya tergolong tinggi. ${ }^{6}$ Untuk itu diperlukan koordinasi yang strategis serta kerjasama yang baik dari berbagai pihak agar tujuan eliminasi filariasis dapat tercapai. Salah satunya dengan melibatkan kader sebagai Tenaga Pelaksana Eliminasi (TPE) filariasis. $^{1}$

Tenaga Pelaksana Eliminasi (TPE) filariasis atau lebih dikenal dengan kader filariasis adalah anggota masyarakat setempat yang terpilih melalui musyawarah masyarakat desa dengan kriteria bersedia, mampu baca tulis, dan disegani oleh masyarakat. Pada umumnya orang yang menjadi TPE bisa berasal dari organisasi yang sudah ada di masyarakat seperti PKK, Karang Taruna, Pramuka, LSM, Guru, tokoh agama, ataupun tokoh masyarakat. Penugasan kader filariasis diutamakan di pos-pos pelaksana POPM filariasis atau kunjungan dari rumah ke rumah. Mereka memiliki peran terpenting pada saat persiapan sampai dengan pelaksanaan pengobatan massal di masing-masing desa. ${ }^{1}$

Pemberian Obat Pencegahan Massal (POPM) filariasis di Kabupaten Banyuasin pada tahun 2015 sudah memasuki pemberian obat pencegahan massal tahap IV. Kegiatan POPM ini tidak lepas dari peran kader sebagai ujung tombak filariasis di lapangan. Berdasarkan hal tersebut penelitian ini bertujuan untuk mengetahui peran kader dalam pelaksanaan kegiatan POPM filariasis pada tahap III di Kabupaten Banyuasin.

\section{METODE}

Penelitian dilakukan di Kabupaten Banyuasin Provinsi Sumatera Selatan. Penelitian ini dilakukan selama 9 bulan (Maret-November 2015). Desain penelitian ini adalah pendekatan kualitatif dengan wawancara mendalam menggunakan pedoman wawancara. Instrumen dalam penelitian ini adalah peneliti sendiri dengan bantuan alat perekam (tape recorder) untuk merekam proses wawancara.

Informan dalam penelitian ini dipilih dengan menggunakan teknik purposive sampling. Informan merupakan pihak-pihak yang terlibat dalam pelaksanaan program POPM filariasis tahap III yaitu: Pengelola Pogram Filariasis Dinas Kesehatan Kabupaten Banyuasin, Pengelola Program Filariasis di Puskesmas Kabupaten Banyuasin, bidan desa, dan kader filariasis. Penelitian ini adalah jenis penelitian kualitatif maka jumlah informan disesuaikan dengan kebutuhan data apabila data sudah menjawab tujuan/pertanyaan penelitian maka jumlah informan dianggap cukup.

Analisis data hasil wawancara dengan menggunakan analisis konten, dimana hasil wawancara mendalam yang terekam baik dalam bentuk catatan maupun pita rekaman ditransfer ke dalam bentuk tulisan. Selanjutnya, data disusun dalam bentuk matrik dan ditampilkan dalam bentuk deskriptif kualitatif.

\section{HASIL}

Kabupaten Banyuasin merupakan salah satu Kabupaten di Provinsi Sumatera Selatan yang terletak di pantai timur Sumatera, dengan luas wilayahnya sekitar 12,18 persen dari luas Provinsi Sumatera Selatan yaitu $11.832 .99 \mathrm{~km}^{2}$ yang tersebar dari daratan hingga perairan. Cukup banyak desa-desa di wilayah perairan yang hanya dapat dijangkau dengan menggunakan speedboat. Kabupaten Banyuasin merupakan daerah endemis filariasis di Provinsi Sumatera Selatan. Jumlah kasus kronis yang dilaporkan sampai tahun 2014 adalah 89 kasus kronis, dimana 45 orang laki-laki dan 35 orang perempuan. Dari 19 kecamatan yang ada sebanyak 15 kecamatan mempunyai kasus filariasis kronis. 
Salah satu faktor yang menjadi ujung tombak keberhasilan program pemberian obat massal filariasis adalah tersedianya Tenaga Pelaksana Eliminasi (TPE) pada tingkat desa. Di Kabupaten Banyuasin, TPE yang digunakan adalah seluruh kader posyandu yang ada di tiap desa atau kelurahan, satu posyandu ratarata mempunyai 5 orang kader, seperti yang disampaikan oleh salah seorang informan :

"...untuk di desa Sukomulyo ada 3 posyandu, jadi per posyandu 5 orang, berarti 15 orang..." (Pengelola Pogram Filariasis Puskesmas).

Begitu juga dengan jumlah kader yang digerakan sebagai TPE filariasis yang masih kurang dan belum bisa menjangkau seluruh masyarakat di wilayahnya berdampak pada rendahnya cakupan pengobatan massal filariasis, seperti yang disampaikan oleh informan berikut:

"...sebenarnya untuk satu posyandu 4 kader itu masih agak kurang...tapi ya bagaimana lagi dananya cuma itu kan..." (Pengelola Program Filariasis Puskesmas).

Sebagaian besar kader yang dilibatkan sebagai TPE filariasis di Kabupaten Banyuasin tidak mendapatkan pelatihan tentang POPM secara intensif, namun hanya sebatas pengarahan yang akan disampaikan ke masyarakat seperti rencana waktu pembagian obat, cara pemberian obat ke masyarakat, dosis obat yang diberikan dan cara minumnya. Seperti yang disampaikan oleh beberapa informan berikut :

"...kalau kader-kadernya biasanya bu...dikasih pengarahan saja misal obatnya dikasih sebanyak ini...." (bidan desa).

“...saat mau mulai pengobatan dikasih obat sama bidan dan kami disuruh untuk membagikan, itu saja..." (kader).

“...iya..hemm ini kamu bagikan seperti itu kata bidannya, nanti kalau obatnya habis ambil lagi di rumah, iya kata saya terus kami bagikan sampai habis..." (kader).

Peran TPE di lapangan pada kegiatan POPM filariasis tahap ketiga di
Kabupaten Banyuasin juga membantu bidan desa atau petugas puskesmas dalam mendata atau menyeleksi masyarakat yang menjadi target POPM filariasis dari rumah ke rumah seperti pernyataan informan berikut :

"...proses penentuannya itu, waktu kemarin datanya door to door dari kader, jadi jumlah berdasarkan penduduk berdasarkan posyandu dulu jadi biar akurat kan maksudnya kan. Di data dulu seluruh dari umur 2 tahun ke atas sampe 70, nanti baru sudah dapat hasil itulah maksudnya sasarannya itulah yang dijadikan sasaran, nanti dikeluarin lagi, dihitung lagi mana yang tidak masuk, misalnya ibu hamilnya berapa, nanti kan itu ada keterangannya di buku itu..." (Pengelola Pogram Filariasis Puskesmas).

Selain melakukan pendataan masyarakat yang menjadi target POPM filariasis dari rumah ke rumah, pendataan juga dilakukan bersamaan dengan pemberian obat massal di pos pengobatan yang telah ditentukan. Namun sebelumnya kader telah mengumumkan tempat dan waktu kegiatan POPM filariasis.

“...waktu pembagian obat itu langsung kami data, kader-kadernya sudah kasih tau pas hari itu disuruh kumpul ke pos baru nanti orang yang datang ditulis namanya sama umurnya langsung ditanya ada maag tidak, kemudian ditensi, nah kalau sasarannya anak kecil yang kurang berat badannya tidak dikasih obat seperti itu..." (kader).

“...di sini kader-kadernya sudah memberi tahu hari untuk disuruh kumpul ke pos baru nanti orangnya dateng ditulis namanya sama umurnya langsung dikasih obat seperti itu..." (bidan desa).

Menggerakan masyarakat untuk datang ke pos-pos pengobatan massal yang telah ditentukan adalah salah satu kegiatan TPE dalam mendukung kesuksesan POPM filariasis. Menurut beberapa informan dalam menggerakan masyarakat, kader bekerjasama dengan aparat desa seperti Ketua RT, sekretaris desa atau kepala desa untuk 
mengumumkan waktu, tempat, kegiatan POPM flariasis. Pengumuman kegiatan pelaksanaan POPM disampaikan juga oleh TPE di kantor kelurahan, pada pertemuan kegiatan RT seperti yasinan atau arisan, di masjid khususnya pada waktu sholat Jum'at seperti yang diungkapkan informan berikut :

"...biasanya kita umumkan di kantor kelurahan, mesjid waktu sholat Jumat atau pas ada acara arisan, yasinan kita sampaikan tanggal sekian-sekian ada pengobatan, pokoknya berbagai upaya kita lakukan biar tercapai target kita..." (kader).

Hal ini juga diperkuat oleh pernyataan salah satu TPE untuk mencapai target sasaran pengobatan dilakukan berbagai upaya selain mengajak ke pos pengobatan dan mendatangi dari rumah ke rumah.

"...ada yang dibagi langsung di pos, ada kami yang ke rumah-rumah, ada saat kegiatan posyandu..sebelum kegiatan biasanya minta bantuan kades untuk mengumpulkan masyarakat kami juga membantu...nanti ada juga kami datang ke sekolah, jadi seperti itu maksudnya..." (kader).

Distribusi adalah suatu rangkaian kegiatan dalam rangka pengeluaran dan pengiriman obat-obatan yang bermutu dari gudang obat secara merata dan teratur untuk memenuhi pesanan atau permintaan unit-unit pelayanan kesehatan. Pendistribusian logistik atau obat filariasis dimulai dari dinas kesehatan kabupaten/kota kemudian ke puskesmas lalu ke bidan desa kemudian kader dan masyarakat.

"...kalau obat itu di drop dari dinas ke puskesmas, dari puskesmas ke kader, dari kader ke masyarakat..." (Pengelola Program Filariasis Dinas Kesehatan Kabupaten Banyuasin).

Distribusi logistik dalam pelaksanaan POMP filariasis di Kabupaten Banyuasin terdistribusi dengan baik, pendistribusian obat filariasis dari puskesmas ke kader biasanya pada saat pertemuan, rapat, atau pelatihan di puskesmas.

"...pada saat rapat biasanya ada kader dan bidan desa sekalian mereka rapat untuk terakhir kali sebelum pelaksanaan. Mereka ambil dulu obat di puskesmas. Jadi orang puskesmas mengambil obat ke dinas menggunakan mobil ambulans, obat di drop di puskesmas, nanti bidan desa ambil ke puskesmas berdasarkan sasaran mereka tadi berapa, berapa orang yang mau dikasi obat itu kemudian nanti dibantu kader membagikan ke masyarakat..." (Pengelola Program Filariasis Puskesmas).

"...saat mau mulai pengobatan, dikasih obat sama bidannya trus kami disuruh bagikan obatnya cuma seperti itu saja..." (kader).

Pada pelaksanaan POMP filariasis tahap III di Kabupaten Banyuasin ketersediaan atau stok obat untuk masing masing desa sudah mencukupi karena dibagi berdasarkan sasaran yang telah ditetapkan, bahkan stok obat tersebut lebih, karena ada penduduk yang menjadi sasaran ditunda pengobatannya, seperti sedang hamil.

“...ada lebih sedikit, kan ada yang nggak minum obat misalnya ibu hamil..." (bidan desa).

Beberapa desa ada yang mengalami kekurangan obat filariasis saat pembagian obat, hal ini disebabkan karena adanya mobilisasi penduduk pendatang ke wilayah mereka dan penduduk pendatang ini tidak tercatat sebagai sasaran pengobatan mereka, seperti kutipan informan berikut:

“...ya sampai kurang obat waktu itu, baru-baru ini banyak pendatang baru di komplek-komplek itu nah..." (kader).

Selain dengan menggerakkan masyarakat ke pos pengobatan filariasis, metode membagikan obat massal filariasis dari rumah ke rumah juga dilakukan. Kendala penduduk enggan minum obat di depan petugas juga masih ditemukan pada pengobatan massal filariasis tahap III ini.

"...ya...door to door...mmmmhh. Tapi kita tidak tahu diminum atau tidak yang penting kita sudah ngasih tau. Dikasih tau cara minumnya kayak gini...yang punya sakit ini...tidak boleh minum. 
Diantar ke rumah...jadi dapat semua. Tapi belum dicek lagi apakah obatnya diminum atau tidak..." (Pengelola Program Filariasis Dinas Kesehatan Kabupaten Banyuasin).

Penduduk yang tidak dapat datang ke pos-pos pengobatan yang telah ditentukan saat kegiatan POPM filariasis selain mendatangi rumah penduduk, TPE memberikan obat pencegahan massal ke penduduk sasaran melalui sekolah yaitu taman kanak-kanak/pendidikan anak usia dini, karena biasanya di TK atau PAUD ada kegiatan posyandu yang dihadiri orang tua, khususnya ibu-ibu. Hal ini tergambar dari pernyataan informan di bawah ini:

"...di sini kan tidak bisa dikumpulin sekaligus, masalahnya kan ada yang datang, ada yang tidak bisa datang, jadi pinter-pinter kita bagaimana mencari waktu. Heemm..paling besok pagi di sekolah, obatnya dibagikan. Kan kalau di PAUD atau TK pasti ada ibunya, jadi sebelumnya anak-anak ini suruh ngomong sama ibu-ibunya nanti disuruh kumpul di posyandu sambil nimbang berat badan, jadi sekalian saja obatnya dibagikan saat itu..." (kader).

Menurut Permenkes RI No. 94 Tahun 2014 tentang Penanggulangan Filariasis, menyebutkkan bahwa sebaiknya obat diminum sesudah makan dan di depan petugas TPE, ${ }^{1}$ agar terkontrol penduduk yang menjadi sasaran pengobatan telah meminum obat filariasis yang telah disiapkan. Akan tetapi, pelaksanaannya sebagian penduduk sasaran tidak langsung minum di depan kader pada saat pembagian obat filariasis di pos-pos pengobatan yang ditentukan atau pada saat pembagian obat ke rumah-rumah oleh TPE, dengan alasan belum makan, sakit, takut efek samping obat, dan diwakili oleh orang lain atau keluarga saat mengambil obat sehingga obat diambil untuk dibawa pulang, akibatnya tidak terpantau apakah penduduk yang menjadi sasaran telah meminum obat yang diberikan. Seperti pernyataan dari informan berikut:

"...nah, memang ada yang langsung diminum tapi ado yang tidak mau diminum di pos, nanti di rumah saja seperti itu, alasannya karena dia belum makan, lagi pening..Nah terus kami kasih tau dosis obatnya..." (kader).

Penduduk sasaran yang tidak minum obat pencegahan filariasis secara langsung di depan petugas TPE perlu dilakukan sweeping, namun di lapangan tidak semua penduduk sasaran pengobatan dilakukan sweeping oleh TPE apakah obat yang diberikan sudah diminum, begitu juga dengan masyarakat yang didatangi rumahnya oleh TPE untuk diberikan obat yang belum diambil di pos pengobatan, seperti pernyataan informan berikut :

"...iya tidak seluruhnya sih ditanyai, pokoknya mana yang ketemu saja baru kami ditanya diminum tidak obatnya kemaren..."(kader).

“...tidak ya, seandainya disuruh kami datangi cuma kami kan tidak disuruh seperti itu...Nah kalau yang door to door itu kita tidak sampai menunggu mereka minum obat depan kita atau tidak, pokoknya obatnya sudah dikasih..." (kader).

Antisipasi munculnya kejadian akibat efek samping obat perlu dilakukan pengawasan yang intensif dari tenaga kesehatan yang berpengalaman (dokter, perawat, bidan) di lapangan. Dokter atau tenaga kesehatan lain harus ada dalam jangkauan selama lima hari mulai hari pemberian obat. Pengawasan efek samping obat filariasis tahap III di Kabupaten Banyuasin pada umumnya dilakukan oleh TPE saat memberi obat dengan mengingatkan kepada penduduk sasaran apabila mengalami gejala-gejala seperti timbul demam, mual, muntah, pusing, sakit sendi dan badan akibat bekerjanya obat dalam membunuh parasit dalam tubuh agar menghubungi TPE yang bertanggungjawab membagikan obat, kemudian TPE tersebut akan menghubungi petugas puskesmas.

“...kemarin itu ada katanya sampai pusing, kalau ada apa-apa kasih tau ke petugas. Banyak juga sih yang pusing itu. Cuman ya kasih tau sebelumnya kalau minum obat itu ada efek sampingnya. Nanti kalau ada yang pusing-pusing suruh hubungin kader, nanti langsung dihubungin petugas..." (kader). 
Beberapa kendala yang dihadapi oleh TPE filariasis di Kabupaten Banyuasin saat melaksanakan pengobatan massal filariasis diantaranya dana operasional yang disediakan pemerintah masih minim dan wilayah Kabupaten Banyuasin yang luas didominasi perairan dengan medan yang berat menyulitkan kader untuk menjangkaunya.

“...ya, keliling-kelilingnya itu berat buat kader... lokasinya Banyuasin itu yang berat karena $75 \%$ perairan semua, trus kalau mau bawa motor cuma beberapa kader yang punya motor..." (Pengelola Program Filariasis Dinas Kesehatan Kabupaten Banyuasin).

Kurangnya jumlah TPE filariasis yang tidak sebanding dengan jumlah penduduk menjadi permasalahan bagi TPE untuk menjangkau seluruh penduduk di wilayahnya.

"...Sebenarnya untuk satu posyandu 4 kader tu masih agak kurang...Tapi ya bagaimana lagi dananya cuma itu kan..."(kader).

\section{BAHASAN}

Keberhasilan dalam program eliminasi filariasis merupakan interaksi dari berbagai faktor yang saling melengkapi sebagai satu kesatuan, contohnya dimana keberhasilan prosedur pengobatan massal filariasis dan kepatuhan penduduk dalam minum obat filariasis tidak bisa dilihat dari satu faktor saja tapi juga tidak lepas dari peran kader sebagai tenaga pelaksana eliminasi filariasis di lapangan. Tenaga Pelaksana Eliminasi (TPE) filariasis merupakan sumber daya yang sangat penting dan merupakan penghubung antara petugas puskesmas dengan masyarakat. Selain itu, mereka berperan dalam memberikan informasi kepada masyarakat tentang tempat, waktu, informasi mengenai filariasis dan pengobatan massal, mengisi kartu pengobatan dan formulir sensus penduduk binaan, menyeleksi dan mencatat penduduk yang ditunda pengobatannya, pendataan kasus kronis filariasis. ${ }^{1}$

Prevalensi mikrofilaria di Kabupaten Banyuasin setelah pengobatan massal tahap III telah mengalami penurunan dari $1,5 \%$ menjadi $0,4 \%$ di tingkat kabupaten, ${ }^{4}$ akan tetapi hasil penelitian Reni Oktarina menunjukkan bahwa hasil Survei Darah Jari yang dilakukan di Desa Sedang menunjukkan angka Mikrofilaria rate (Mfrate) masih relatif tinggi meskipun tidak mencapai $1 \%(0,96 \%){ }^{6}$ Artinya meskipun telah terjadi penurunan $M f$ rate hingga $<1 \%$ tidak berarti bahwa penularan filariasis sudah tidak terjadi lagi. Pemberian obat secara massal akan mengurangi kepadatan mikrofilaria secara cepat, akan tetapi apabila terdapat kontribusi penderita dengan kepadatan mikrofilaria rendah atau penderita yang tidak patuh dalam minum obat maka akan mempertahankan rantai penularan filariasis. Hal ini berkaitan dengan adanya perubahan kepadatan mikrofilaria yang rendah menjadi kepadatan tinggi apabila tidak ada pengobatan yang diberikan kepada penderita.

Masih tingginya kepadatan mikrofilaria berdasarkan hasil penelitian Reni Oktarina menunjukkan masih adanya potensi penularan yang cukup tinggi dan mempertahankan rantai penularan filariasis apabila tidak ada pengobatan kepada penderita atau penderita yang tidak patuh dalam minum obat. ${ }^{7}$ Hasil penelitian di Alor menyebutkan bahwa 1 responden mengalami peningkatan kepadatan mikrofilaria dari 88 menjadi $1356 \mathrm{Mf} / \mathrm{ml}$ dan setelah ditelusuri responden tidak minum obat pada tahap pertama pengobatan dengan alasan efek samping dari obat yang membuat pusing. ${ }^{8}$ Untuk itu setiap orang yang tinggal di daerah dengan kepadatan filaria tertentu akan diberi obat sehingga kepadatan mikrofilaria menurun ${ }^{9}$ seperti yang dilakukan di Kabupaten Banyuasin.

$$
\text { Hasil penelitian ini juga }
$$

menggambarkan bahwa yang menjadi kendala atau hambatan program eliminasi filariasis di Kabupaten Banyuasin pada tahap III ini adalah belum dapat diatasinya efek samping yang ditimbulkan akibat pemberian obat massal filariasis, hal ini dapat mempengaruhi keengganan masyarakat minum obat. Beberapa hasil penelitian juga menemukan hal yang sama bahwa efek samping yang dirasakan masyarakat sering mengakibatkan mereka tidak mau melanjutkan minum obat filariasis pada tahun berikutnya dan terkadang menyebabkan trauma pada penderita filariasis. ${ }^{10}$ Untuk itu peran TPE sebagai pelaksana teknik utama di lapangan harus 
mampu menjelaskan, mensosialisasikan, dan memotivasi masyarakat agar tetap minum obat tanpa mengabaikan efek samping yang timbul. Tanpa adanya penjelasan informasi tentang pengobatan massal filariasis masyarakat mungkin tidak mau minum obat filariasis dan akhirnya mereka menjadi berisiko dalam transmisi penularan filariasis. ${ }^{11}$ Kenyataannya di lapangan cukup banyak TPE yang tidak mampu menjelaskan efek samping obat massal filariasis dan mereka juga belum mampu memotivasi masyarakatnya untuk tetap minum obat sehingga keengganan masyarakat minum obat filariasis masih tinggi.

Faktor pengetahuan kader sebagai tenaga pelaksana eliminasi khususnya mengenai efek samping obat serta pencegahan dan cara mengatasinya yang masih kurang menjadi salah satu penyebab. Sebagian besar kader di Kabupaten Banyuasin tidak mendapatkan pelatihan tentang POPM filariasis secara intensif. Mereka hanya diundang dalam rangka sosialisasi untuk membantu petugas kesehatan dalam hal ini petugas puskesmas maupun bidan desa terkait kegiatan pembagian obat di wilayahnya. Informasi terkait efek samping obat memang mereka dapatkan selain informasi rencana pembagian obat dan dosis obat yang mereka bagikan, namun informasi terkait efek samping ini masih minim akibatnya TPE tidak dapat menjelaskan secara baik tentang efek samping obat dan cara yang dilakukan untuk mengatasi efek samping tersebut, mereka hanya mengarahkan atau menyarankan untuk segera melapor ke bidan atau petugas puskesmas jika ditemukan masyarakat yang mengalami efek samping obat.

Kurangnya komunikasi dan informasi dari petugas kesehatan terhadap masyarakat menjadi penyebab rendahnya cakupan pengobatan massal. ${ }^{12}$ Hasil penelitian Anggi Gian Saputra dkk juga menjelaskan hal yang sama bahwa hasil analisis pengetahuan sebagian besar TPE memiliki tingkat pengetahuan yang rendah. Hal ini disebabkan karena masih banyaknya petugas TPE yang tidak mengetahui informasi tentang filariasis dan program pengobatan filariasis sehingga menyebabkan kinerja tenaga pelaksana eliminasi tidak optimal. ${ }^{13}$ Pelatihan merupakan faktor yang dapat meningkatkan motivasi para kader sebagai TPE dalam pelaksanaan program POPM filariasis disamping pemberian insentif. ${ }^{14}$

Adanya peran kader juga oleh tokoh masyarakat dan petugas kesehatan sangat dibutuhkan dalam hal penyebaran informasi yang intens untuk memberikan penjelasan atau penyuluhan tentang cara minum obat yang benar untuk mengurangi efek samping dan meminimalisir penolakan masyarakat untuk minum obat. Pada umumnya masyarakat lebih sering mendengarkan anjuran yang disampaikan oleh kader, tokoh masyarakat atau petugas kesehatan setempat. ${ }^{15}$ Menjelang pengobatan kurang dari 1 bulan sebaiknya diadakan sosialisasi POPM oleh kader, tokoh masyarakat atau petugas kesehatan setempat tentang penyakit filariasis sehingga masyarakat dapat melaksanakan pengobatan dan menyikapi dengan benar apabila terjadi reaksi pengobatan.

Kader sebagai ujung tombak di lapangan dan sebagai perpanjangan tangan petugas kesehatan mempunyai peran yang penting dalam mensosialisasikan ke masyarakat tentang pentingnya minum obat filariasis untuk itu seorang kader perlu memahami tentang filariasis sehingga mereka dapat menyebarkan informasi atau pengetahuan mereka kepada masyarakat. Selain itu, kader sebagai anggota unit terkecil di masyarakat (keluarga) dapat memberi pengetahuan juga kepada anggota keluarganya sendiri. ${ }^{16}$ Peran dan fungsi kader kesehatan menurut Effendi dan Makhfuldli (2019) dalam Lasbudi adalah meningkatkan keikutsertaan masyarakat dalam upaya pembangunan kesehatan melalui pendekatan edukatif yaitu berusaha menimbulkan kesadaran untuk dapat memecahkan masalah dengan memperhitungkan sosial budaya setempat, diharapkan masyarakat termotivasi untuk mengikuti program pemerintah dalam pemberantasan filariasis. ${ }^{17}$

Pembagian obat massal filariasis di Kabupaten Banyuasin pada umumnya dilakukan dengan dua cara, yaitu mengumpulkan masyarakat di pos-pos pengobatan tertentu dan membagikan obat dari rumah ke rumah kepada keluarga yang belum mendapatkan obat. Pembagian obat 
yang dilakukan dari rumah ke rumah dimaksudkan untuk meningkatkan cakupan POPM filariasis sehingga tujuan dan keberhasilan program dapat tercapai. Hasil penelitian di Tanjung Jabung Timur disebutkan bahwa pemberian obat filariasis dengan cara membagi dari rumah ke rumah merupakan cara yang efektif untuk mencapai sasaran penduduk yang harus minum obat. ${ }^{18}$ Waktu dan metode POPM filariasis yang tepat dapat menentukan luasan sasaran penerima obat. Lansia akan lebih tepat jika dibagikan dari rumah ke rumah, usia sekolah dibagikan di sekolah waktu kegiatan belajar, pegawai negeri atau swasta dibagikan saat sore sampai malam baik melalui pos pengobatan atau rumah ke rumah.

Tidak semua penduduk sasaran pengobatan dilakukan pemantauan oleh TPE dikarenakan kurangnya sumber daya manusia (SDM) dari segi kuantitas. Kurangnya SDM menjadi kendala yang dihadapi dalam melaksanakan POPM filariasis di Kabupaten Banyuasin. Tenaga Pelaksana Eliminasi (TPE) filariasis tidak bisa menjangkau seluruh penduduk di wilayahnya khususnya pada wilayahwilayah perairan yang medannya cukup sulit dan jauh. Hal yang sama terjadi di Kabupaten Bandung dimana kurangnya sumber daya manusia (SDM) dalam pemberantasan filariasis. ${ }^{19}$ Penelitian di Sumba Tengah juga mendapatkan bahwa kader atau petugas kesehatan yang ada belum seluruhnya melaksanakan tugas dan fungsinya, khususnya dalam penyuluhan dan kunjungan rumah. ${ }^{20}$ Kebutuhan sumber daya manusia tidak hanya diperlukan pada saat pelaksanaan, namun juga dibutuhkan saat pemantauan dan monitoring. Penduduk sasaran yang tidak datang ke pos pengobatan harus didatangi oleh TPE. Kegiatan pemantauan ini meliputi pemberian obat bagi sasaran yang belum menerima obat, bagi penduduk yang menolak minum obat harus menandatangani formulir yang menyatakan bahwa mereka menolak minum obat, serta pemantauan jika ada yang bermasalah dengan kesehatan karena efek samping pengobatan.

Selain itu, minimnya anggaran untuk kader mengakibatkan banyak kegiatan yang seharusnya dilakukan menjadi terhambat, seperti anggaran untuk transportasi kader dalam melakukan pendataan maupun pembagian obat dari rumah ke rumah. Sejalan dengan hasil penelitian di Kabupaten Mamuju Utara bahwa tidak tersedianya anggaran mengakibatkan banyak kegiatan yang seharusnya dilakukan sebelum proses pembagian obat di masyarakat tidak dapat dilakukan seperti pendataan, pelatihan serta pemantauan minum obat. ${ }^{21}$

Agar target cakupan minum obat meningkat dan target $M f$ rate $<1 \%$ dapat tercapai pentingnya pengawasan minum obat dalam pengobatan massal. ${ }^{7}$ Pengawasan atau monitoring minum obat pada kegiatan POPM filariasis ini dilakukan oleh TPE, baik dilakukan dengan mendatangi ke rumah-rumah atau di pos obat. Dalam pengawasan dan monitoring masyarakat diminta untuk minum obat filariasis di depan kader. Permasalahannya di Kabupaten Banyuasin pengawasan minum obat masih rendah khususnya pada masyarakat yang telah mengambil obat, namun tidak minum obat dihadapan petugas. Peran TPE memotivasi masyarakat untuk minum obat di depan mereka masih rendah dimana TPE tidak bisa memaksa agar masyarakat minum obat di depan mereka. Hasil penelitian di India juga menggambarkan hal yang sama bahwa penyebab rendahnya cakupan minum obat selain adanya efek samping juga disebabkan adanya pemberian obat yang tidak diawasi. ${ }^{8}$

Pencatatan dan pelaporan pelaksanaan kegiatan POPM telah sesuai dengan alur, yaitu dimulai dari pencatatan oleh TPE kemudian dilaporkan ke puskesmas, puskesmas kemudian mengumpulkan laporan dari setiap desa untuk dikirim ke dinas kesehatan.

Permasalahannya laporan tersebut belum tercatat dengan baik berapa jumlah cakupan penduduk yang minum obat. Sebagian besar TPE hanya mencatat penduduk yang menerima obat artinya ini menunjukkan tidak terpantaunya penduduk sasaran yang minum obat filariasis masih menjadi permasalahan di Kabupaten Banyuasin, padahal dengan adanya pelaporan yang baik dari TPE diharapkan dapat menjadi acuan bagi Dinas Kesehatan Kabupaten Banyuasin untuk penyusunan 
anggaran dalam menjalankan program eliminasi filariasis sehingga program eliminasi yang dicanangkan oleh pemerintah dapat berhasil.

Belum optimalnya peran supervisi dari puskesmas dalam mengawasi kinerja kader sebagai tenaga pelaksana eliminasi filariasis di Kabupaten Banyuasin juga berdampak pada kinerja kader. Hal ini sejalan dengan hasil penelitian di Kabupaten Semarang bahwa kurangnya pengawasan dari petugas puskesmas kepada tenaga pelaksana eliminasi selama melakukan kegiatan POPM menyebabkan kinerja tenaga pelaksana eliminasi tidak optimal. ${ }^{13}$

Sosialisasi terkait POPM filariasis harus sesuai dengan karakteristik masyarakat setempat dengan bahasa yang dipahami penduduk. Penyampaian informasi tentang filariasis di Kabupaten Banyuasin pada umumnya dilakukan pada saat sholat Jum'at, acara arisan ataupun di kegiatan sekolah merupakan cara yang ideal berbasis masyarakat sehingga informasi terkait kegiatan pengobatan POPM filariasis cepat tersosialisasi ke masyarakat. Perbaikan cara promosi kesehatan dan peningkatan rasa peduli dapat meningkatkan kepatuhan pengobatan dapat melibatkan tokoh agama dan tokoh masyarakat. $^{22}$

\section{KESIMPULAN}

Peran tenaga pelaksana eliminasi (TPE) dalam pelaksanaan POPM filarisis tahap III di Kabupaten Banyuasin belum maksimal, hal ini disebabkan tidak adanya pelatihan secara intens dan khusus untuk kader sebelum pelaksanaan POPM filariasis dimulai, masih kurangnya SDM kader sebagai TPE, anggaran untuk mobilisasi TPE juga masih minim, pengawasan dan supervisi oleh petugas puskesmas terhadap kinerja TPE juga masih rendah.

\section{SARAN}

Perlu dilakukan pelatihan-pelatihan yang lebih intens dan khusus untuk TPE agar pemahaman mereka mengenai filariasis serta efek sampingnya dapat meningkat dan akhirnya akan meningkatkan cakupan minum obat filariasis, perlu dilakukan tambahan anggaran mobilisasi petugas TPE untuk menjangkau penduduk di wilayahnya dan adanya pengawasan beserta supervisi yang melekat dari petugas puskesmas terhadap kinerja TPE.

\section{UCAPAN TERIMA KASIH}

Terima kasih kepada yang terhormat Bapak Dr. Feri Ahmadi, MPH sebagai reviwer dalam penulisan artikel ini. Kepala Balai Litbangkes Baturaja dan tim peneliti.

\section{KONTRIBUSI PENULIS}

IM dan RO sebagai kontributor utama dalam penulisan ini yang bertanggung jawab pada konsep, analisis data, metodelogi, mengkaji hasil, penelusuran referensi, kesimpulan dan saran.

\section{DAFTAR PUSTAKA}

1. Kementerian Kesehatan Republik Indonesia. Peraturan Menteri Kesehatan Republik Indonesia No. 94 Tahun $2014 \quad$ Tentang Penanggulangan Filariasis.; 2014.

2. Portunasari WD, Kusmintarsih ES, Riwidiharso E. Survei Nyamuk Culex spp . sebagai Vektor Filariasis di Desa Cisayong , Kecamatan Cisayong , Kabupaten Tasikmalaya. Biosfera. 2016;33(3):142-148. doi:10.20884/1.mib.2016.33.3.36.

3. PP\&PL D. Profil Subdit Filariasis Dan Schistomiasis Tahun 2010. Jakarta; 2010.

4. Dinas Kesehatan Kabupaten Banyuasin. Laporan Tahunan Eliminasi Penyakit Kaki Gajah Kabupaten Banyuasin Propinsi Sumatera Selatan Tahun 2010.; 2010.

5. Dinas Kesehatan Kabupaten Banyuasin Propinsi Sumatera Selatan Tahun 2018. Data Dasar Filariasis Kabupaten Banyuasin Propinsi Sumatera Selatan Tahun 2018.; 2018.

6. Oktarina, $R$, santoso, Taviv $Y$. Gambaran Angka Prevalensi Mikrofilaria di Kabupaten Banyuasin Pasca Pengobatan Massal Tahap III. Balaba. 2017;13(1):11-20. 
7. Suryaningtyas $\mathrm{NH}$, Arisanti $\mathrm{M}$, Satriani AV, Inzana N, Santoso S, Suhardi S. Kondisi Masyarakat pada Masa Surveilans PascaTransmission Assessment Survey ( TAS ) -2 Menuju Eliminasi Filariasis di Kabupaten Bangka Barat, Bangka Belitung. Bul Penelit Kesehat. 2018;46(1):35-44.

8. Supali $T$, Djuardi $\mathrm{Y}$, Bradley $\mathrm{M}$, Noordin R, Ruckert P, Fischer PU. Impact of Six Rounds of Mass Drug Administration on Brugian Filariasis and Soil-Transmitted Helminth Infections in Eastern Indonesia. PLoS Negl Trop Dis. 2013;7(12):1-9. doi:10.1371/journal.pntd.0002586.

9. Purwantyastuti. Pemberian Obat Massal Pencegahan (POMP) Filariasis. Bul Jendela Epidemiol. 2010;1(1):15-19.

10. Purnomo I, Supriyo, Hidayati S. Pengaruh Faktor Pengetahuan dan Petugas Kesehatan Terhadap Konsumsi Obat Kaki Gajah (Filariasis) di Kelurahan Bligo Kecamatan Buaran Kabupaten Pekalongan. Pena J Ilmu Pengetah Dan Teknol. 2015;28(1):13-37.

11. Garjito TA, Jastal, Rosmini, $H A$, Srikandi $Y$, Labatjo $Y$. Filariasis dan Beberapa Faktor Yang Berhubungan dengan Penularannya di Desa Pangku-Tolole Kecamatan Ampibabo Kabupaten Parigi-Moutong Provinsi Sulawesi Tengah. vektora. 2013;5(2):54-65.

12. Bhullar N, Maikere J. Challenges in mass drug administration for treating lymphatic filariasis in Papua , Indonesia. Parasites and Vectors. 2010;3(70):1-7.

13. Saputra AG, Saraswati LD, Nissa Kusariana. Gambaran Kinerja Tenaga Pelaksana Eliminasi Filariasis Dalam Pelaksanaan POPM Filariasis di Kabupaten Semarang (Studi di Wilayah Kerja Puskesmas Dadapayam). J Kesehat Masy. 2020;8(2):238-242.

14. Hendri J, Ipa M, Ginanjar A, Yuliasih Y, Astuti EP. Intervensi Kader dalam
Mendukung Program Pemberian Obat Massal Pencegahan (POPM) Filariasis di Kecamatan Cibeureum dan Cibingbin Kabupaten Kuningan Provinsi Jawa Barat. J Ekol Kesehat. 2018;17(1):31-40.

15. Astuti EP, Mara Ipa, Wahono T, Ruliansyah A. Analisis Perilaku Masyarakat Terhadap Kepatuhan Minum Obat Filariasis di Tiga Desa Kecamatan Majalaya Kabupaten Bandung Tahun 2013. Media Litbangkes. 2014;24(4):199-208.

16. Ipa M, Astuti EP, Hakim L, Fuadzy H. Analisis Cakupan Obat Massal Pencegahan Filariasis Di Kabupaten Bandung Dengan Pendekatan Model Sistem Dinamik. BALABA. 2016;12(1):31-38. doi:10.22435/blb.v12i1.4470.31-38.

17. Ambarita LP, Taviv $\mathrm{Y}$, Sitorus $\mathrm{H}$, Pahlevi RI, Kasnodiharjo. Perilaku Masyarakat Terkait Penyakit Kaki Gajah di Kecamatan Pemayung Kabupaten Batanghari, Jambi. Media Litbangkes. 2014;24(4):191-198. doi:10.22435/mpk.v24i4.3673.191198.

18. Santoso, Sri Cahyaningrum. ReTransmission Assessment Survey Filariasis Pasca Pengobatan Massal di Kabupaten Agam , Provinsi Sumatera Barat Tahun 2016. Balaba. 2017;13(2):143-152.

19. Ipa M, Astuti EP, Ruliansyah A, Wahono T, Hakim L. Gambaran Surveilans Filariasis Di Kabupaten Bandung Provinsi Jawa Barat. J Ekol Kesehat. 2014;13(2):153-164.

20. Lobo V, Bulu AK, Noshirma M. Pemberian Obat Massal Pencegah Filariasis di Desa Mbilur Pangadu, Kabupaten Sumba Tengah. Media Litbangkes. 2018;28(3):167-174.

21. Nurjana MA, Anastasia $\mathrm{H}$, Chadijah $\mathrm{S}$, Nyoman N. Studi Kualitatif Peran Petugas Kesehatan dan Kader Desa Dalam Program Pengobatan Massal Filariasis di Kabupaten Mamuju Utara Provinsi Sulawesi Barat Tahun 2015. Spirakel. 2018;10(1):31-40. 
22. Ambarwati, Dwi Pratiwi. Evaluasi Program Eliminasi Filariasis Melalui POPM Filariasis Dengan Minum Obat Di Tempat. J Profesi Keperawatan. 2018;5(2):1-15. 